the wrong reasons. The technology and political climate of the 1960 s were simply too challenging to maintain a presence on the Moon. We therefore missed out on the most important science that would have emerged from a sustained lunar base. Lunar observatories peering at the cosmos from that pristine surface, advanced field-geology expeditions and basic physics experiments searching for gravitational waves await us in the future.

Jack O. Burns is at the Office of Research and in the Department of Physics \& Astronomy, University of Missouri, 205 Jesse Hall, Columbia, Missouri 65211, USA.

\section{Taking the horror out of shocks}

Electroshock: Restoring the Mind

by Max Fink

Oxford University Press: 1999. 157 pp.

$\mathfrak{1} 13.95, \$ 22$

\section{Hugh Freeman}

In an America long besotted with psychotherapy, Max Fink carried an often lonely torch for the physical treatment of psychiatric disorders. Electroconvulsive therapy (ECT) has been in worldwide use for 60 years and has proved to be one of the safest procedures in medicine, with a very high success rate in appropriate cases. One might have thought that this would have given it a good public image, but no amount of research seems able to dispel the myth largely promoted by anti-psychiatrists that ECT damages the functioning of the brain. People mostly take their cue from alarming images of it such as those seen in the film One Flew Over the Cuckoo's Nest, rather than from scientific results or the testimony of millions of people who have been helped by the treatment.

Fink has written a non-technical account of ECT primarily to inform the public, but also to challenge those many mental-health professionals (particularly in the United States) whose knowledge of it is inadequate or out of date. Electroshock is a slim volume, packing a punch of controversy. Critics have tended to claim sarcastically that induced fits were introduced on the basis of a wrong theory, and that if they do work, no one knows how. If that is so, it certainly wouldn't be either the first or last time this has happened in medicine. The art is essentially empirical, and many interventions that have helped patients have their rationales elucidated only much later.

In fact, Fink points out that the whole thing wasn't nearly as daft as is often made out. The background was a total absence of effective treatment for mental disorders in

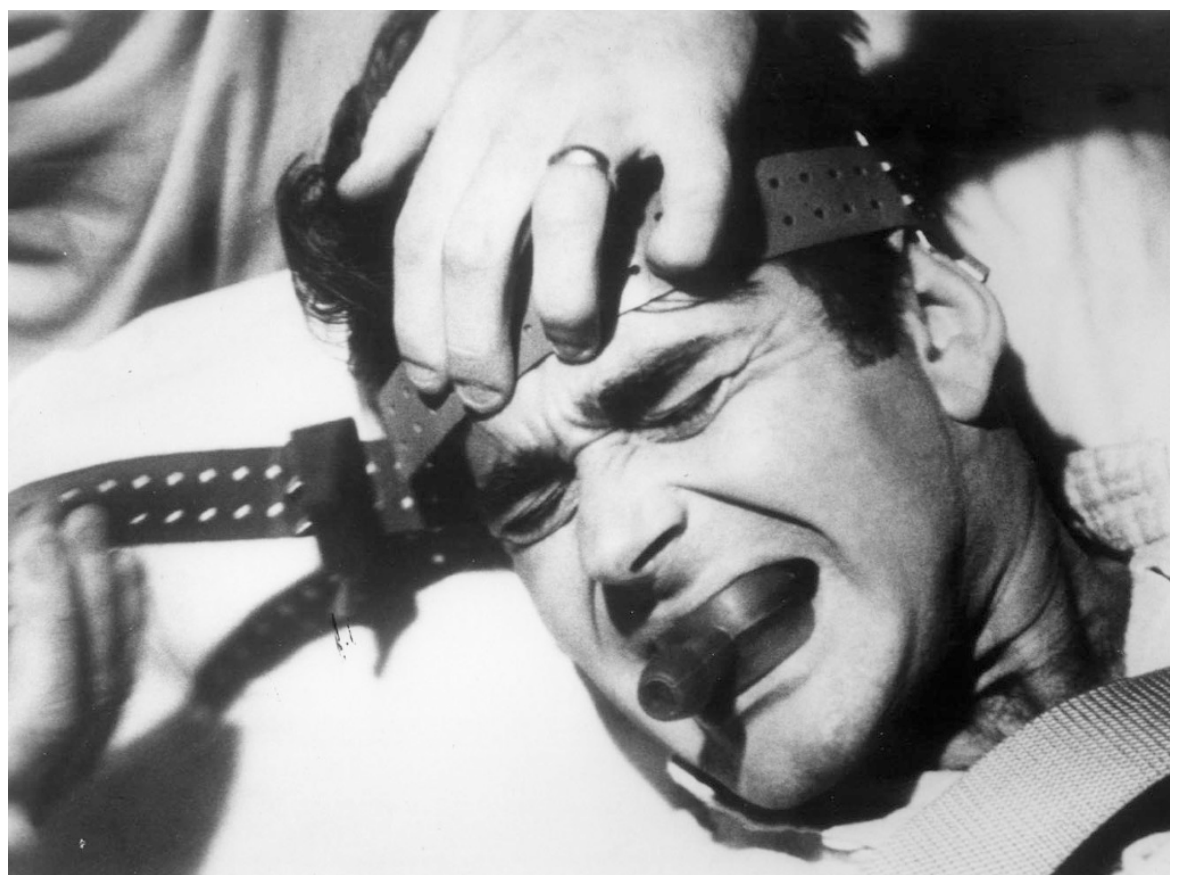

Electrifying image: films such as Shock Treatment give this useful therapy a sensationalist name.

the early twentieth century. Since Pasteur had shown that high temperatures could destroy bacteria, the induction of a new disorder (fever) might antagonize an existing one. On that basis, Julius Wagner-Jauregg in Vienna successfully treated neurosyphilis with malaria. It had also been observed that schizophrenic patients occasionally recovered after developing epilepsy through a head injury or infection. Ladislaus Meduna in Budapest therefore proposed that artificial epilepsy might be a useful treatment for schizophrenia. This was long before any antipsychotic drugs were available.

As is now well known, the results in the treatment of schizophrenia were mixed, but when the same procedure was tried in patients with severe depression, its effect seemed miraculous - some 20 years before the first antidepressants. In time, the original convulsive injections were replaced by a more acceptable electrical current, while anaesthesia, muscle relaxants and continuous oxygen removed most of the unpleasant aspects of the procedure. In folk memory, though, and in many media representations of ECT, things have hardly changed.

One major drawback of Fink's account is an overly American focus. Fink describes how ECT tended to be abandoned with the rise of psychotherapy and psychopharmacology, was "rediscovered" in the 1970s, is still ignored in university teaching centres and is still legally and financially restricted.

But in Europe, practically none of this happened, although local restrictions occurred in The Netherlands and similar regulations have just been introduced in Italy, and restrictive regulations have just been introduced in Italy. Where Britain failed, as Fink rightly points out, is in allow- ing obsolete or poorly maintained equipment to remain in use, not providing electro-encephalographic monitoring, and not training young psychiatrists in the method adequately. This reflects the lack of resources afflicting the UK mental-health services. In the United States, things are now even worse, with few public or Veterans hospitals offering ECT at all and the rigid treatment algorithms of 'managed care' having little place for it.

Professionals will find the clinical and scientific parts of Fink's work more controversial. For a start, he believes he knows how it works. In mental illness, "the hormones are wildly disordered", but impulses from the central part of the brain in an induced fit stimulate the hypothalamus to discharge products that gradually regulate the whole endocrine pattern of the body. It may or may not be so, but proof is needed; and the immensely complex actions of the neurotransmitters seem to have been ignored.

Fink advocates ECT for a wider range of disorders and in much longer courses than is advised in other standard references. However, his choice of clinical response as the essential guide would be generally accepted. It is true that ECT often doesn't get a fair trial because clinicians give it up too quickly. But not much attention is given to an experimental method that may well replace ECT. Rapid transcranial stimulation aims to produce the same effects without the need for a fit or unconsciousness. It's too soon to say whether this will mean the end of ECT, but until then, Fink is right to try and persuade us to make the best use of what we have. Hugh Freeman, former editor of the British Journal of Psychiatry, is at Green College, Oxford OX2 6HG, UK. 